\title{
Linking renewables and fossil fuels with carbon capture via energy storage for a sustainable energy future
}

\author{
Dawid P. Hanak (凶), Vasilije Manovic \\ Energy and Power Theme, School of Water, Energy and Environment, Cranfield University, Bedford, Bedfordshire, MK43 0AL, UK
}

(C) The Author(s) 2019. This article is published with open access at link.springer.com and journal.hep.com.cn

\begin{abstract}
Renewable energy sources and low-carbon power generation systems with carbon capture and storage (CCS) are expected to be key contributors towards the decarbonisation of the energy sector and to ensure sustainable energy supply in the future. However, the variable nature of wind and solar power generation systems may affect the operation of the electricity system grid. Deployment of energy storage is expected to increase grid stability and renewable energy utilisation. The power sector of the future, therefore, needs to seek a synergy between renewable energy sources and low-carbon fossil fuel power generation. This can be achieved via wide deployment of CCS linked with energy storage. Interestingly, recent progress in both the CCS and energy storage fields reveals that technologies such as calcium looping are technically viable and promising options in both cases. Novel integrated systems can be achieved by integrating these applications into CCS with inherent energy storage capacity, as well as linking other CCS technologies with renewable energy sources via energy storage technologies, which will maximise the profit from electricity production, mitigate efficiency and economic penalties related to CCS, and improve renewable energy utilisation.
\end{abstract}

Keywords carbon capture, energy storage, renewable energy sources, decarbonisation, fossil fuels

\section{Introduction}

The power sector of 2050 is expected to rely primarily on renewable energy sources, with support from fossil fuel power generation with $\mathrm{CO}_{2}$ capture and storage (CCS), and nuclear power plants [1]. However, differences in operating patterns and interactions among these technologies will

Received April 30, 2019; accepted August 2, 2019

E-mail: d.p.hanak@cranfield.ac.uk affect the operation of the electricity network [2]. CCS is expected to impose significant efficiency and economic penalties [3], and therefore cannot be perceived as an ultimate solution to climate change. Its integration to the fossil fuel power plant fleet will act, however, as a bridge to a clean, reliable and sustainable electricity supply. CCS is also essential for decarbonisation of carbon-incentive industries and direct air capture.

In the scenarios assuming larger than $50 \%$ share of renewable energy sources and nuclear power plants operating at base load in the power sector in $2050[4,5]$, the flexible fossil fuel power plants will be responsible for balancing electricity supply and demand (Fig. 1). However, variable load operation of such systems retrofitted with CCS, not considering their energy storage capabilities, is expected to impose even higher efficiency and economic penalties when compared with base-load operation [6]. Nevertheless, utilising the inherent energy storage capabilities of CCS technologies can not only improve the system flexibility, but also improve the economic feasibility of CCS [7]. It needs to be highlighted that the flexibility of CCS has only been evaluated in relation to the flexibility of the fossil fuel power generation itself. The inherent energy storage capabilities of CCS have not yet been explored to store energy from renewable energy sources, thereby reducing the need for their curtailment. Importantly, the greatest challenge of renewable energy sources, a variability of electricity supply that would impose additional operating costs [8], can be mitigated by the deployment of energy storage that can decouple electricity supply and demand. These systems have the potential for improving not only the flexibility of the electricity system, but also the energy utilisation, as the excess energy from renewable energy sources can be stored rather than wasted [9]. Importantly, energy storage could contribute to $\mathrm{CO}_{2}$ emission reduction only for high penetration levels of renewable energy sources or other low-carbon power generation technologies, such as decarbonised fossil fuel power plants. Otherwise, energy 


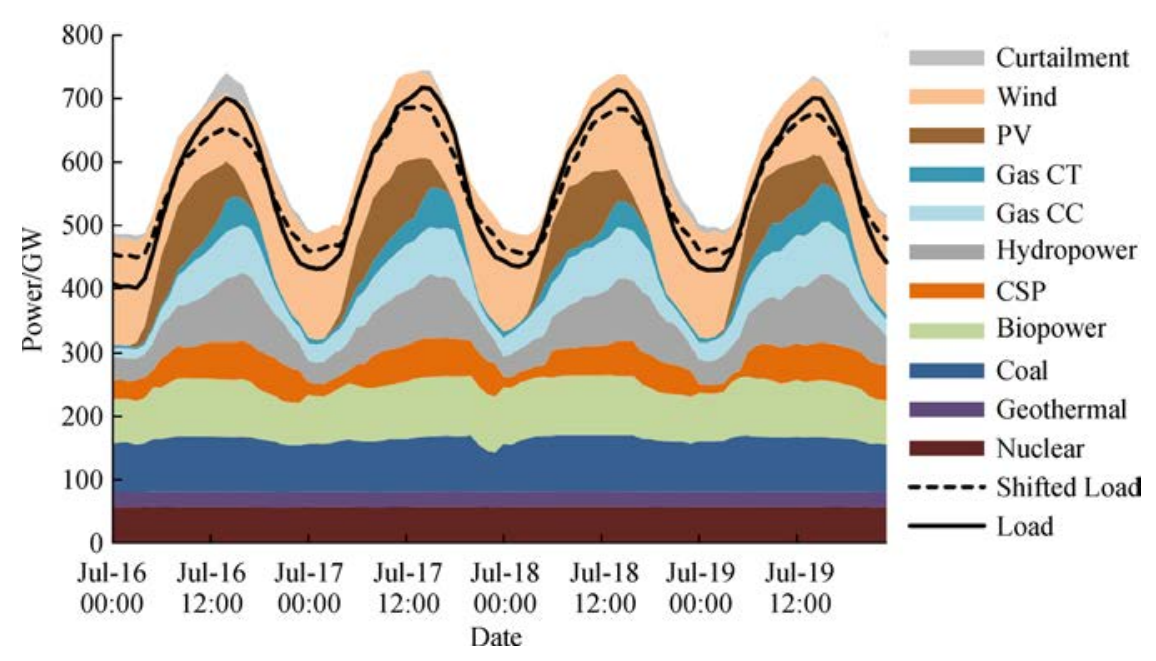

Fig. 1 Predicted demand and supply profile for the power sector in 2050. Reproduced from the National Energy Technology Laboratory [4], copyright (C) National Energy Technology Laboratory 2012.

storage could increase $\mathrm{CO}_{2}$ emissions, the extent of which depends on carbon prices and the share of unabated coalbased generation in the power sector [10].

CCS can act, at least, as a bridge from fossil fuel reliance to the clean electricity system. Among different options for energy storage, calcium looping and liquid oxygen storage have the potential to act as direct links between renewable energy sources and fossil fuel power generation. Therefore, the power sector of the future needs to seek a synergy between renewable energy sources and low-carbon fossil fuel power generation that leads to both reduced curtailment of renewable energy sources and reduced economic penalties of CCS. This work aims to provide an overview of potential links between CCS and renewable energy sources using energy storage, as well as a perspective on the development of innovative integrated systems for the low-carbon power sector, which will ensure the security of energy supply with low environmental footprint and at an affordable cost of electricity. Benefits of such an approach are then presented in two case studies that propose to use liquid oxygen storage and sorbent storage linked with calcium looping and oxy-combustion CCS technologies.

\section{Links between energy storage and car- bon capture}

Among available energy storage technologies, such as mature pumped-hydro storage plants that account for $95 \%$ of global energy storage capacity [11], thermal, electrochemical and mechanical energy storage systems have gained significant attention recently, particularly in conjunction with concentrating solar power plants $[9,12-14]$. The recent literature indicates that there are technologies that can be successfully utilised for both energy storage and decarbonisation of fossil fuel power plants.
A thermochemical mechanism for thermal energy storage, in which heat is used to drive the endothermic chemical reaction (charging mode) and is released in the reverse reaction (discharging mode), is claimed to offer high energy densities [15], especially if one of the products in the regeneration stage is in the vapour phase [16]. Alternatively, heat can be stored in the form of sensible or latent heat via a change of the storage medium temperature or phase, respectively $[12,15]$. The former is the simplest and cheapest of all thermal energy storage mechanisms, yet the low thermal capacity of the available storage materials would require a large size of the storage equipment. The latter, on the other hand, offers higher storage density and isothermal nature of the storage process. The greatest challenges of phase change materials are degradation of their cycling performance and high cost $[12,15]$. As the thermochemical mechanism allows long-term energy storage, as long as the reactants are stored separately, and the stored energy is almost completely recovered, it is regarded as a viable and effective route for long-term thermal energy storage and transport [15]. A calcium looping $(\mathrm{CaL})$ process, which involves either hydration or carbonation of $\mathrm{CaO}$, was first proposed for energy storage in the mid-1970s [16,17] and has been considered among the best candidates for energy storage [14,15], especially when linked with concentrating solar power plants [18]. The carbonation reaction offers nearly $50 \%$ higher theoretical thermal energy density $\left(1222 \mathrm{kWh} \cdot \mathrm{m}^{-3}\right)$ compared to the hydration reaction $\left(833 \mathrm{kWh} \cdot \mathrm{m}^{-3}\right)$. However, some technical challenges need to be resolved prior to the large-scale deployment of $\mathrm{CaL}$ for energy storage, including the lack of electricity storage capability [19], loss of sorbent performance over time in continuous operation [16], and the requirement for temporary $\mathrm{CO}_{2}$ storage [15].

The utilisation of cryogenic liquid energy storage was 
proposed for electricity storage in the late 1970s [20] and has also been shown to be a feasible option for storage of electricity generated in renewable energy sources [9]. This technology is based on the liquefaction of air, and the potential separation of oxygen in the air separation unit, which requires electricity for air compression (charging mode). The product can then be stored at a low temperature and low pressure in an insulated storage tank [21], which overcomes the main drawback of compressed air energy storage-dependence on the availability of proper geological formations [22]. The liquid product could then be pressurised, vaporised and expanded to atmospheric pressure, producing electricity on demand (discharging mode). In the case of energy storage via liquid oxygen storage, oxygen can be vaporised, and then utilised in the oxy-combustion process $[23,24]$. The key benefit of liquid air and oxygen energy storage is their high energy density of 172 [25] and $313 \mathrm{kWh} \cdot \mathrm{m}^{-3}$ [26], respectively, in contrast to the low energy density of up to $6 \mathrm{kWh} \cdot \mathrm{m}^{-3}$ of compressed air energy storage [27]. The only challenge of this technology is the requirement for proper insulation to ensure operation in a cryogenic region.

Currently, more than $38 \%$ of global electricity is generated in relatively low-cost and reliable coal-fired power generation systems, associated with more than $30 \%$ of the global $\mathrm{CO}_{2}$ emissions [28]. It has been estimated that retrofitting these systems with mature $\mathrm{CO}_{2}$ capture technologies, such as amine scrubbing which is regarded as the technology of choice for $\mathrm{CO}_{2}$ capture [29], would impose up to a $10 \%$-point penalty on the power plant efficiency [3]. As a result, the cost of electricity from fossil fuel power generation with CCS is predicted to increase, and to be comparable to that from renewable energy sources [5]. The increase in the cost of electricity associated with CCS could be further reduced through optimisation of the mature $\mathrm{CO}_{2}$ separation technologies, such as oxy-combustion which can achieve an efficiency penalty of 5\%-11\% points [30], and the development of novel $\mathrm{CO}_{2}$ capture technologies, such as $\mathrm{CaL}$ which has been shown to reduce the efficiency penalty to $5 \%-9 \%$ points [31].

Although the inherent energy storage capability of $\mathrm{CaL}$ and potential implementation of liquid oxygen storage in oxy-combustion power plants make these processes an excellent choice for a direct link between the fossil fuel and renewable energy sources, there is a potential for other $\mathrm{CO}_{2}$ capture technologies, such as chemical looping combustion and mature amine scrubbing, to be linked with energy storage technologies for improved economic performance. Namely, energy storage can be deployed in chemical looping combustion via high-temperature oxygen carrier storage, if linked with a concentrating solar receiver [32], or, if this technology is utilised for hydrogen production [33], via the power-to-gas scheme to store energy in the form of synthetic natural gas [34]. Finally, amine scrubbing can benefit from energy storage via steam accumulators [35], phase change materials, such as molten salts, sensible heat storage solids [36], and solvent storage [37].

Potential links between CCS with energy storage and renewable energy sources could reduce the efficiency penalties associated with the integration of $\mathrm{CO}_{2}$ capture to fossil fuel power plants, and at the same time, increase the profitability of the entire system. Importantly, in scenarios with high penetration levels of renewable energy sources $(30 \%-40 \%)$, the integration cost is predicted to account for more than $50 \%$ of the generation cost [38]. As this cost is mainly associated with balancing the electricity supply and demand to make up for the intermittency of renewable energy sources and flexible operation of fossil fuel power plants, efficient energy storage technologies are required to handle the electricity network interactions.

\section{Representative case studies}

The parallel development of $\mathrm{CaL}$ for both storage of energy in renewable energy sources and decarbonisation of fossil fuel power generation reveals that application of this process is a technically viable and efficient option in both cases. Similarly, the potential implementation of liquid oxygen energy storage into an air separation unit, which is a part of $\mathrm{CaL}$ and the oxy-combustion power plant, appears to be a technically feasible option [26,39]. To utilise the benefits of both the low-carbon fossil fuel power plant and energy storage, the system would operate in charging mode during off-peak periods, when electricity price is low, to produce and store active sorbent (CaL only) and/or liquid oxygen (CaL and oxy-combustion). During peak demand periods, when the electricity price is high, the parasitic load imposed by the $\mathrm{CO}_{2}$ capture systems, primarily coming from the power requirement for the air separation and $\mathrm{CO}_{2}$ compression unit ( $\mathrm{CaL}$ and oxy-combustion), and heat requirement for sorbent regeneration $(\mathrm{CaL}$ only), would be reduced by discharging the energy stored (Fig. 2).

Such operation of the low-carbon fossil fuel power plant with energy storage would increase the net power output of the integrated system, leading to higher economic profit in this period. As shown in Fig. 3, the coal-fired power plant with $\mathrm{CaL}$ and energy storage via sorbent or liquid oxygen storage can become more profitable than the reference coal-fired power plant if the carbon tax exceeds 9.7 and $8.3 € / t_{\mathrm{CO}_{2}}$, respectively, which is below the value of carbon tax reported in July $2019\left(27-29 € / \mathrm{t}_{\mathrm{CO}_{2}}\right)[40]$. Moreover, the daily profit of the oxy-combustion coal-fired power plant with liquid oxygen energy storage would bring higher daily profit for a carbon tax higher than $29.2 € / \mathrm{t}_{\mathrm{CO}_{2}}$. This higher value in the latter case is a result of higher average efficiency penalty associated with the oxy-combustion system (11.2\% points) compared with that of the $\mathrm{CaL}$ system (8.7\% points). This is caused by conservative assumptions regarding heat and work inte- 


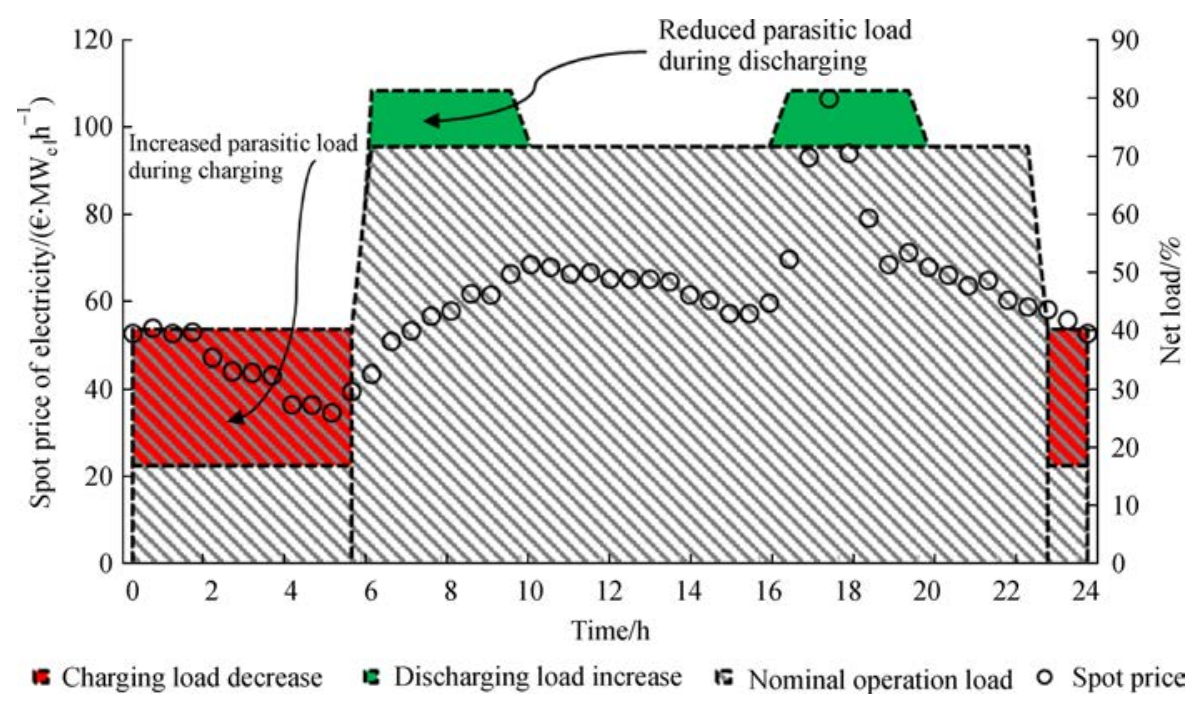

Fig. 2 Representative operating principle of low-carbon fossil fuel power plants linked with energy storage.

gration between the air separation and $\mathrm{CO}_{2}$ compression unit, and the steam cycle in the oxy-combustion system. Nevertheless, it can be stated that the reduction in the parasitic load of $\mathrm{CO}_{2}$ capture will bring a further increase in the daily profit. Moreover, retrofits of $\mathrm{CaL}$ were shown to increase the net power output of the entire system by up to $50 \%$, leading to higher revenue from electricity sales compared with that of the oxy-combustion system. Nevertheless, implementation of liquid oxygen storage in both cases resulted in the entire process becoming more profitable than processes with no energy storage. Further increases in profit can be achieved via determination of the optimal charging and discharging time. It is also noteworthy that the addition of energy storage capability has been shown to have a low impact on the total capital cost. Namely, implementation of the sorbent storage system to $\mathrm{CaL}$, which is characterised with a reference capital cost of $8 € \cdot \mathrm{MW}_{\text {th,sensible }}{ }^{-1}$ [41], would increase the specific capital cost by $0.6 € \cdot \mathrm{kW}_{\mathrm{el}}{ }^{-1}$. Similarly, implementation of a liquid oxygen storage system, characterised with a reference capital cost of $320 € \cdot \mathrm{m}^{-3}$ [23], would increase the specific capital cost of $\mathrm{CaL}$ and the oxycombustion system by 2.3 and $1.7 € \cdot \mathrm{kW}_{\mathrm{el}} \mathrm{h}^{-1}$, respectively. Such characteristics of these $\mathrm{CO}_{2}$ capture systems linked with the energy storage system make them competitive compared with other key energy storage technologies (Table 1).

Importantly, $\mathrm{CaL}$ for $\mathrm{CO}_{2}$ capture with inherent energy storage capacity can solve the challenges reported in Section 2 for its application only as an energy storage system. Namely, such process can accommodate excess electricity generated from renewable energy sources to satisfy the process power requirement, which arises mostly from the air separation unit and $\mathrm{CO}_{2}$ compression unit, and has a permanent source of $\mathrm{CO}_{2}$ from the fossil fuel power plant. Moreover, the heat requirement for sorbent regeneration can be provided by a concentrating solar plant [18]. Furthermore, the sorbent performance can be improved through a sorbent hydration stage, leading to operation with higher average conversions [43], and thus higher energy densities. However, the system with sorbent reactivation via hydration was found to have inferior

Table 1 Comparison of the considered inherent energy storage technologies with other key energy storage technologies [27,42]

\begin{tabular}{|c|c|c|c|}
\hline Technology & Energy density $/\left(\mathrm{kW}_{\mathrm{el}} \mathrm{h} \cdot \mathrm{m}^{-3}\right)$ & Lifetime /years & Specific capital cost $/\left(€ \cdot \mathrm{kW}_{\mathrm{el}} \mathrm{h}^{-1}\right)$ \\
\hline Liquid oxygen storage & 313 & $20-40^{\text {a) }}$ & $1.7-2.3$ \\
\hline Solid sorbent storage & 1222 & $5-30^{\mathrm{b})}$ & 0.6 \\
\hline Pumped hydro storage & $0.5-2$ & $40-60$ & $4-80$ \\
\hline Flywheel & $20-80$ & $15-20$ & $800-11000$ \\
\hline Compressed air storage & $3-6$ & $20-40$ & $2-100$ \\
\hline Li-ion batteries & $150-500$ & $5-15$ & $500-3000$ \\
\hline Capacitor & $2-10$ & $1-10$ & $320-800$ \\
\hline Thermal energy storage & $80-500$ & $5-30$ & $3-500$ \\
\hline
\end{tabular}

a) Assumed the same as for compressed air storage; b) assumed the same as for thermal energy storage systems. Further work is required to assess their lifetime when considered simultaneously for $\mathrm{CO}_{2}$ capture and energy storage. 


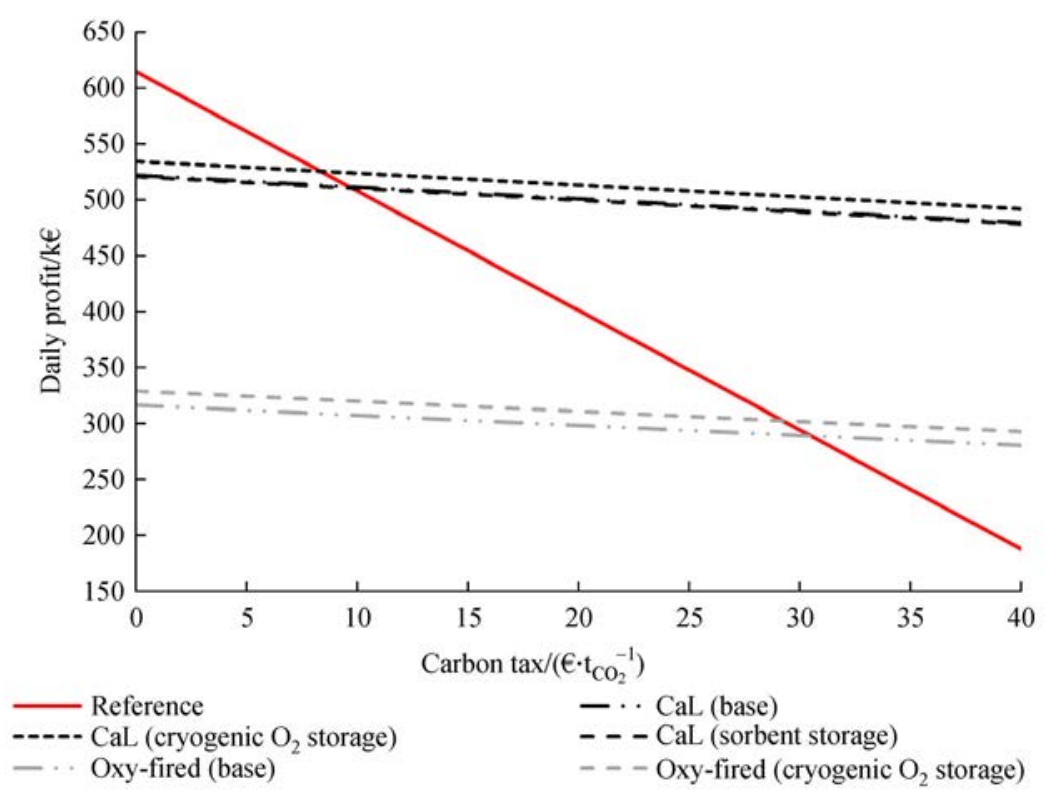

Fig. 3 Effect of carbon tax on daily profit. The analysis has been conducted using the methodology described in the Electronic Supplementary Material (ESM).

economic performance compared with the system without reactivation, due to lower power output, and thus lower revenue from electricity sales [26]. Similarly, the oxycombustion system with liquid oxygen energy storage can accommodate excess electricity generated from renewable energy sources to meet the process parasitic load and to produce liquid oxygen for future utilisation. In addition, the value of linking $\mathrm{CO}_{2}$ capture systems with energy storage systems should be determined at the industry level, using the system level feasibility assessment approach [44].

\section{Perspective for the low-carbon power sector}

Flexible operation of the $\mathrm{CO}_{2}$ capture system linked with the energy storage system would maximise the profit from electricity production, mitigate economic penalties related to $\mathrm{CO}_{2}$ capture, and improve utilisation of the energy generated from renewable energy sources. Hence, commercial deployment of integrated systems, which link renewable energy sources and fossil fuels with carbon capture via energy storage, would contribute to decarbonisation of the energy sector, ensuring sustainable, reliable and affordable electricity. The links between CCS and energy storage have not been well established yet. It also remains unclear whether utilising the inherent energy storage capability of $\mathrm{CO}_{2}$ capture technologies will affect their lifetime and performance. Therefore, further work is required to demonstrate not only the value that such integrated systems would add to the energy system, but also their technical feasibility via experimental testing. It is also noteworthy that CCS is not only a bridge to lowcarbon power generation systems, but also essential for decarbonisation of carbon-intensive industries, such as cement, steel, and lime industries, as well as its use in direct air capture. Therefore, both the power and industrial sectors will benefit from linking renewable energy sources and fossil fuels with carbon capture via energy storage, making these sectors environmentally friendly and economically attractive at the same time.

Acknowledgements This publication is based on research conducted within the "Redefining power generation from carbonaceous fuels with carbonate looping combustion and gasification technologies" project funded by UK Engineering and Physical Sciences Research Council (EPSRC reference: EP/P034594/1). Data underlying this study can be accessed through the Cranfield University repository at $10.17862 /$ cranfield. rd. 8973440

Open Access This article is licensed under a Creative Commons Attribution 4.0 International License, which permits use, sharing, adaptation, distribution and reproduction in any medium or format, as long as you give appropriate credit to the original author(s) and the source, provide a link to the Creative Commons licence, and indicate if changes were made. The images or other third party material in this article are included in the article's Creative Commons licence, unless indicated otherwise in a credit line to the material. If material is not included in the article's Creative Commons licence and your intended use is not permitted by statutory regulation or exceeds the permitted use, you will need to obtain permission directly from the copyright holder. To view a copy of this licence, visit http://creativecommons.org/licenses/by/4.0/.

Electronic Supplementary Material Supplementary material is available in the online version of this article at https://doi.org/10.1007/s11705-0191892-2 and is accessible for authorized users. 


\section{References}

1. IEA. Tracking Clean Energy Progress. Paris: IEA Publications, 2019

2. Akrami A, Doostizadeh M, Aminifar F. Power system flexibility: An overview of emergence to evolution. Journal of Modern Power Systems and Clean Energy, 2019, 7(5): 987-1007

3. Bui M, Adjiman C S, Bardow A, Anthony E J, Boston A, Brown S, Fennel P S, Fuss S, Galindo A, Hackett L A, et al. Carbon capture and storage (CCS): The way forward. Energy \& Environmental Science, 2018, 11(5): 1062-1176

4. NREL. Renewable Electricity Futures Study. Golden: National Energy Technology Laboratory, 2012

5. Pierpont B, Nelson D, Goggins A, Posner D. Flexibility. The Path to Low-Carbon, Low-Cost Electricity Grids. London: Climate Policy Initiative, 2017

6. Arias B, Criado Y A, Sanchez-Biezma A, Abanades J C. Oxy-fired fluidized bed combustors with a flexible power output using circulating solids for thermal energy storage. Applied Energy, 2014, 132: $127-136$

7. Chalmers H, Gibbins J, Leach M. Valuing power plant flexibility with CCS: The case of post-combustion capture retrofits. Mitigation and Adaptation Strategies for Global Change, 2012, 17(6): 621649

8. Edenhofer O. King coal and the queen of subsidies. Science, 2015, 349(6254): 1286-1287

9. Mahlia T M I, Saktisahdan T J, Jannifar A, Hasan M H, Matseelar H S C. A review of available methods and development on energy storage: Technology update. Renewable \& Sustainable Energy Reviews, 2014, 33: 532-545

10. Ummels B C, Kling W L, Pelgrum E. Integration of large-scale wind power and use of energy storage in the Netherlands' electricity supply. IET Renewable Power Generation, 2008, 2(1): 34-46

11. DOE. DOE Global Energy Storage Database. 2019

12. Gil A, Medrano M, Martorell I, Lázaro A, Dolado P, Zalba B, Cabeza L F. State of the art on high temperature thermal energy storage for power generation. Part 1-Concepts, materials and modellization. Renewable \& Sustainable Energy Reviews, 2010, 14(1): 31-55

13. Hou Y, Vidu R, Stroeve P. Solar energy storage methods. Industrial \& Engineering Chemistry Research, 2011, 50(15): 8954-8964

14. Gur I, Sawyer K, Prasher R. Searching for a better thermal battery. Science, 2012, 335(6075): 1454-1455

15. Yan T, Wang R Z, Li T X, Wang L W, Fred I T. A review of promising candidate reactions for chemical heat storage. Renewable \& Sustainable Energy Reviews, 2015, 43: 13-31

16. Ervin G. Solar heat storage using chemical reactions. Journal of Solid State Chemistry, 1977, 22(1): 51-61

17. Barker R. The reversibility of the reaction $\mathrm{CaCO}_{3} \rightleftarrows \mathrm{CaO}+\mathrm{CO}_{2}$. Journal of Applied Chemistry \& Biotechnology, 1973, 23(10): 733742

18. Ortiz C, Valverde J M, Chacartegui R, Perez-Maqueda L A, Giménez P. The calcium-looping $\left(\mathrm{CaCO}_{3} / \mathrm{CaO}\right)$ process for thermochemical energy storage in concentrating solar power plants. Renewable \& Sustainable Energy Reviews, 2019, 113: 109252

19. Akinyele D O, Rayudu R K. Review of energy storage technologies for sustainable power networks. Sustainable Energy Technologies and Assessments, 2014, 8: 74-91

20. Smith E M. Storage of electrical energy using supercritical liquid air. Proceedings of the Institution of Mechanical Engineers, 1977, 191 (1): 289-298

21. Kantharaj B, Garvey S, Pimm A. Compressed air energy storage with liquid air capacity extension. Applied Energy, 2015, 157: 152164

22. Zhang Y, Yang K, Hong H, Zhong X, Xu J. Thermodynamic analysis of a novel energy storage system with carbon dioxide as working fluid. Renewable Energy, 2016, 99: 682-697

23. Hu Y, Li X, Li H, Yan J. Peak and off-peak operations of the air separation unit in oxy-coal combustion power generation systems. Applied Energy, 2013, 112: 747-754

24. Jin B, Su M, Zhao H, Zheng C. Plantwide control and operating strategy for air separation unit in oxy-combustion power plants. Energy Conversion and Management, 2015, 106: 782-792

25. Morgan R, Nelmes S, Gibson E, Brett G. Liquid air energy storage - Analysis and first results from a pilot scale demonstration plant. Applied Energy, 2015, 137: 845-853

26. Hanak D P, Biliyok C, Manovic V. Calcium looping with inherent energy storage for decarbonisation of coal-fired power plant. Energy \& Environmental Science, 2016, 9(3): 971-983

27. Luo X, Wang J, Dooner M, Clarke J. Overview of current development in electrical energy storage technologies and the application potential in power system operation. Applied Energy, 2015, 137: 511-536

28. IEA. Global Energy \& $\mathrm{CO}_{2}$ Status Report. Paris: IEA Publications, 2018

29. Rochelle G T. Amine scrubbing for $\mathrm{CO}_{2}$ capture. Science, 2009, 325 (5948): 1652-1654

30. Perrin N, Dubettier R, Lockwood F, Tranier J P, Bourhy-Weber C, Terrien P. Oxycombustion for coal power plants: Advantages, solutions and projects. Applied Thermal Engineering, 2015, 74: 7582

31. Hanak D P, Michalski S, Manovic V. From post-combustion carbon capture to sorption-enhanced hydrogen production: A state-of-theart review of carbonate looping process feasibility. Energy Conversion and Management, 2018, 177: 428-452

32. Ma Z, Martinek J. Analysis of solar receiver performance for chemical-looping integration with a concentrating solar thermal system. Journal of Solar Energy Engineering, 2019, 141(2): 021003

33. Chiesa P, Lozza G, Malandrino A, Romano M, Piccolo V. Threereactors chemical looping process for hydrogen production. International Journal of Hydrogen Energy, 2008, 33(9): 2233-2245

34. Bailera M, Lisbona P, Romeo L M, Espatolero S. Power to gasbiomass oxycombustion hybrid system: Energy integration and potential applications. Applied Energy, 2016, 167: 221-229

35. Swithenbank J, Finney K N, Chen Q, Yang Y, Nolan A, Sharifi V N. Waste heat usage. Applied Thermal Engineering, 2013, 60(1-2): 430-440

36. Zhao R, Deng S, Zhao L, Liu Y, Tan Y. Energy-saving pathway exploration of CCS integrated with solar energy: Literature research and comparative analysis. Energy Conversion and Management, 2015, 102: 66-80

37. Mechleri E, Fennell P S, Mac Dowell N. Optimisation and 
evaluation of flexible operation strategies for coal- and gas-CCS power stations with a multi-period design approach. International Journal of Greenhouse Gas Control, 2017, 59: 24-39

38. Hirth L, Ueckerdt F, Edenhofer O. Integration costs revisited - an economic framework for wind and solar variability. Renewable Energy, 2015, 74: 925-939

39. Hanak D P, Powell D, Manovic V. Techno-economic analysis of oxy-combustion coal-fired power plant with cryogenic oxygen storage. Applied Energy, 2017, 191: 193-203

40. Market Insider. $\mathrm{CO}_{2}$ European Emission Allowances Price. 2019

41. Ma Z, Glatzmaier G, Mehos M. Fluidized bed technology for concentrating solar power with thermal energy storage. Journal of Solar Energy Engineering, 2014, 136(3): 031014

42. Chen H, Cong T N, Yang W, Tan C, Li Y, Ding Y. Progress in electrical energy storage system: A critical review. Progress in Natural Science, 2009, 19(3): 291-312

43. Manovic V, Anthony E J. Steam reactivation of spent CaO-based sorbent for multiple $\mathrm{CO}_{2}$ capture cycles. Environmental Science \& Technology, 2007, 41(4): 1420-1425

44. Heuberger C F, Staffell I, Shah N, Mac Dowell N. Quantifying the value of $\mathrm{CCS}$ for the future electricity system. Energy \& Environmental Science, 2016, 9(8): 2497-2510 